Available online:

http://journal.imla.or.id/index.php/arabi

IMLA

Arabi : Journal of Arabic Studies, 2 (2), 2017, 141-155

DOI: http://dx.doi.org/10.24865/ajas.v2i2.61

\title{
KAJIAN PRAGMATIK KESANTUAN BERBAHASA ARAB PADA NOVEL KAUKAB AMUN KARYA SALLY MAGDI
}

\author{
Siti Aminah \\ Universitas Gadjah Mada Yogyakarta, Indonesia \\ E-mail : aminah_arb@ugm.ac.id
}

\begin{abstract}
This article discusses the politeness in Arabic speech especially on the politeness strategies used by the characters in the novel Kaukab Amün. By utilizing Brown and Levinson's view of politeness, it is concluded that in order for communication to be smooth and harmonious, speakers and hearer use positive and negative politeness strategies. The strategy of positive politeness that is done in order to maintain the proximity between the speaker and the hearer is realized in the form of avoiding conflict, involving the opponent in a certain activity/speaker activity, promising, giving praise, expressing jokes, giving attention and sympathy, using certain identity identifiers, asking approval, and showing optimism. The negative politeness strategy is done by using the indirect sentence, reducing the strength or the threat to the speech partner, using the apology expression, and paying respects to the hearer. In the dialogue between characters in the novel Kaukab Amün face threatenings were found, both positive and negative face threathening and the characters use the face saving act strategies.
\end{abstract}

Keywords: politeness, positive face, negative face, face act-threatening

\section{Abstrak}

Artikel ini membahas kesopanan dalam kalimat bahasa Arab terutama tentang strategi kesopanan yang digunakan di dalam novel Kaukab Amün. Dengan menggunakan konsep kesopanan Brown dan Levinson, disimpulkan bahwa agar komunikasi menjadi lancar dan harmonis, pembicara dan pendengar menggunakan strategi kesant unan positif dan negatif. Strategi kesopanan positif dilakukan untuk menjaga jarak antara pembicara dan pendengar dalam bentuk menghindari konflik, melibatkan lawan dalam aktivitas /pembicara tertentu, menjanjikan, memberi pujian, mengekspresikan lelucon, memberi perhatian dan simpati, menggunakan pengenal identitas tertentu, meminta persetujuan, dan menunjukkan optimisme. Strategi kesantunan negatif dilakukan dengan menggunakan kalimat tidak langsung, mengurangi kekuatan atau ancaman terhadap lawan bicara, dengan menggunakan ekspresi maaf, dan memberikan penghormatan kepada pendengarnya. Dalam dialog antarkarakter dalam novel Kaukab Amunn, ditemukan bentuk menghadapi ancaman, baik ancaman wajah positif maupun negatif dan karakternya menggunakan strategi face saving act.

Kata Kunci: kesopanan, positive face, negative face, face act-threatening 


\section{Arabi : Journal of Arabic Studies}

\section{Pendahuluan}

Bahasa sebagai sistem lambang yang berupa bunyi dan bersifat arbitrer digunakan oleh masyarakat tutur untuk bekerjasama, berkomunikasi, dan mengidentifikasi diri (Chaer, 1997: 1). Dalam berkomunikasi, penutur dan mitra tutur menggunakan strategi-strategi tertentu agar komunikasi dapat berjalan dengan baik, sehingga pesannya dapat dimengerti mitra tutur sekaligus menjaga hubungan sosial antara keduanya. Salah satu strategi untuk menjamin lancarnya proses komunikasi antara penutur dan mitra tutur adalah kesantunan. Hal ini penting diperhatikan agar peserta tutur sama-sama merasa dihargai serta menjaga jarak sosial antara keduanya dalam proses berkomunikasi. Kesantunan dalam peristiwa tutur diwujudkan dalam tindak tutur.

Kesantunan berbahasa dapat diartikan sebagai sebuah penunjukan mengenai kesadaran terhadap wajah orang lain (Yule, 2006: 104). Wajah seseorang akan mengalami ancaman ketika seorang penutur menyatakan sesuatu yang mengandung ancaman terhadap harapan-harapan individu yang berkenaan dengan nama baiknya sendiri (Zainurrahman, 2011).

Sebagaimana komunikasi pada umumnya, dalam komunikasi berbahasa Arab para peserta tutur harus memperhatikan kesantunan agar komunikasi dapat berjalan dengan baik. Kesantunan dapat dilihat dari bahasa tutur yang diamati secara langsung dan bahasa tulis. Salah satunya adalah novel. Oleh sebab itu, artikel ini mendeskripsikan strategi kesantunan berbahasa Arab dengan memperhatikan dialog-dialog antartokoh dalam novel Kaukab Amün karya Sally Magdi. Novel yang bergenre realisme magis ini menceritakan tentang kehidupan kerajaan Amūn yang meninggali sebuah planet. Di dalamnya, terdapat dialog-dialog yang kompleks antartokoh, di antaranya raja Amūn, keluarga raja, pegawai kerajaan, dan rakyat. Dengan adanya variasi tokoh, banyak pula bentuk kesantunan berdasarkan kelas sosial yang berbeda pula. Oleh karena itu, artikel ini akan menjelaskan bentuk tuturan dalam novel Kaukab Amūn serta strategi kesantunan tokoh-tokoh pada novel tersebut dalam tuturan.

Beberapa penelitian mengenai kesantunan berbahasa telah dilakukan. Hamed (2014), misalnya, membandingkan strategi kesopanan dan ketidaksopanan komunikasi talkshow penutur bahasa Arab mesir dan bahasa Inggris dengan memanfaatkan teori kesopanan Brown dan Levinson (1987) tentang kesopanan serta Culpeper (1996) tentang ketidaksopanan. Penelitian tersebut menunjukkan persamaan dan perbedaan antara keduanya. Kedua kelompok penutur bahasa tersebut sama-sama menggunakan strategi positif daripada negatif. Kedua kelompok tutur tersebut juga jarang menggunakan ketidaksopanan. Adapun perbedaan antara keduanya adalah penutur bahasa Mesir menggunakan kesopanan negatif lebih banyak daripada penutur bahasa Inggris. Konteks talkshow olahraga membuktikan bahwa teori yang dikemukakan Brown dan Levinson dapat diaplikasikan.

Farenkia (2014) meneliti respons mahasiswa Cape Breton University (Canada) dalam merespons pujian pada delapan situasi. Data dikumpulkan dengan mengisi kuesener dari 25 responden yang menggunakan respons yang kompleks (berterima kasih, mengomentari) terhadap muka pemberi pujian. Ucapan 'terima kasih' menjadi respons dominan terhadap pujian yang diberikan. Namun demikian, para responden tidak menggunakan respons pujian negatif.

Wijayanto dkk. (2013) meneliti kesopanan dalam tuturan mengeluh (komplain). Penelitian tersebut menyimpulkan bahwa para penerima keluhan masih menjaga hubungan baik dengan orang yang menuturkan keluhan. Beberapa strategi kesopanan tergantung pada level dan jarak status sosial yang berbeda-beda. Data diambil dari 50 orang Indonesia pembelajar bahasa Inggris yang terdiri atas 25 laki-laki dan 25 wanita. Strategi kesopanan Brown dan Levinson digunakan dalam menyampaikan keluhan. Strategi bald on record dan kesopanan negatif paling banyak digunakan. Strategi off-record jarang digunakan dalam lintas level dan stat us sosial.

Aubed (2012) membandingkan kesopanan permintaan dalam bahasa Inggris dan Arab. Dalam meminta orang lain melakukan sesuatu, penutur menggunakan tindak tutur lokusi, ilokusi, dan perlokusi. Ekspresi permintaan dalam bahasa Arab dan bahasa Inggris tidak sama. Kesopanan dipandang sebagai kontak antara para peserta tutur untuk menjaga komunikasi di antara keduanya. 
Aziz (2000) meneliti cara masyarakat Indonesia melakukan penolakan melalui ucapan yang menurutnya mengandung nilai-nilai kesantunan tersendiri. Hal ini sekaligus menunjukkan bahwa terdapat bidang baru dalam kajian kebahasaan, bukan hanya dari aspek tata bahasa, bukan pula dari aspek psikososial, namun juga dari aspek etika.

Fegali (1997) mengkritisi penelitian mengenai komunikasi kultural dalam dunia Arab. Komunikasi kultural dapat dilihat dari berbagai perspektif, yaitu nilai dasar budaya, bahasa dan komunikasi verbal, nonverbal dan pola paralinguistik. Dengan mengetahui ketiga hal tersebut dapat dilakukan pengajaran komunikasi transbudaya, terutama dengan masyarakat di kawasan budaya Arab.

Leech memberikan definisi pragmatik sebagai studi tentang makna dalam hubungannya dengan situasi ujar (speech situation) (Leech, 1993). Hal yang sama diungkapkan oleh Cruse (2000) yang memberi acuan pragmatik sebagai ilmu bahasa yang mempelajari pemakaian dan penggunaan bahasa yang selalu harus ditentukan oleh konteks situasi tutur di dalam masyarakat dan wahana kebudayaan yang mewadahi dan melatarbelakanginya.

Sebagai retorika personal, pragmatik membutuhkan prinsip kesopanan (Leech, 1983: 16). Prinsip kesopanan dalam suatu interaksi didefinisikan sebagai alat yang digunakan untuk menunjukkan kesadaran tentang wajah orang lain (Yule, 1996: 60). Prinsip kesopanan terbagi dalam enam maksim, yaitu (1) maksim kebijaksanaan, (2) maksim kemurahan, (3) maksim penerimaan, (4) maksim kerendahan hati, (5) maksim kecocokan, dan (6) maksim kesimpatian. Prinsip kesopanan ini berhubungan dengan dua peserta percakapan, yakni diri sendiri (self) dan orang lain (other). Adapun penjelasan singkat mengenai masing-masing maksim adalah sebagai berikut.

a) Maksim kebijaksanaan. Maksim ini menggariskan setiap peserta pertuturan untuk meminimalkan kerugian orang lain atau memaksimalkan keuntungan bagi orang lain. Dalam hal ini, Leech dalam Wijana (1996) mengatakan bahwa semakin panjang tuturan seseorang semakin besar pula keinginan orang itu untuk bersikap sopan kepada lawan bicaranya. Demikian pula tuturan yang diutarakan secara tidak langsung lazimnya lebih sopan dibandingkan dengan tut uran yang diutarakan secara langsung.

b) Maksim kemurahan. Maksim kemurahan menuntut setiap peserta pertuturan untuk memaksimalkan rasa hormat kepada orang lain, dan meminimalkan rasa tidak hormat kepada orang lain.

c) Maksim penerimaan. Maksim ini mewajibkan setiap peserta tindak tutur untuk memaksimalkan kerugian bagi diri sendiri dan meminimalkan keuntungan diri sendiri.

d) Maksim kerendahan hati. Maksim kerendahan hati berpusat pada diri sendiri. Maksim ini menuntut setiap peserta pertuturan untuk memaksimalkan ketidakhormatan pada diri sendiri dan meminimalkan rasa hormat pada diri sendiri.

e) Maksim kecocokan. Maksim kecocokan menggariskan setiap penutur dan lawan tutur untuk memaksimalkan kecocokan diantara mereka dan meminimalkan ketidakcocokan di antara mereka.

f) Maksim kesimpatian. Maksim kesimpatian mengharuskan setiap peserta pertuturan untuk memaksimalkan rasa simpati, dan meminimalkan rasa antipati kepada lawan tuturnya. Jika lawan tutur mendapatkan kesuksesan atau kebahagiaan, penutur wajib memberikan ucapan selamat. Bila lawan tutur mendapat kesusahan atau musibah, penutur layak berduka atau mengutarakan bela sungkawa sebagai tanda kesimpatian.

Brown dan Levinson (1987) merumuskan prinsip kesantunannya ke dalam lima strategi, yaitu:

1) melakukan tindak tutur secara apa adanya, tanpa basa-basi, dengan mematuhi prinsip kerjasama grice;

2) melakukan tindak tutur dengan menggunakan kesantunan positif; 


\section{Arabi : Journal of Arabic Studies}

3) melakukan tindak tutur dengan menggunakan kesantunan negatif;

4) melakukan tindak tutur secara off records; dan

5) tidak melakukan tindak tutur atau diam saja.

Bersikap santun artinya harus memperhatikan "wajah" atau "muka", baik penutur maupun mitra tutur (Brown dan Levinson 1987). Wajah merupakan atribut pribadi yang dimiliki oleh setiap orang dan bersifat universal (Brown dan Levinson 1987). "Wajah" dalam konteks ini adalah public image, "harga diri", penghargaan yang diberikan masyarakat (Aziz, 2008). Wajah berupa wajah dengan keinginan positif (positive face) dan wajah dengan keinginan negatif (negative face). Wajah positif terkait dengan nilai solidaritas, ketakformalan, pengakuan, dan kesetiakawanan, sedangkan wajah negatif bermuara pada keinginan seseorang untuk tetap mandiri, bebas dari gangguan pihak luar, dan adanya penghormatan pihak luar terhadap kemandiriannya itu (Aziz, 2008: 2). Dengan kata lain, negative face adalah kebutuhan untuk mandiri dan positive face adalah kebutuhan untuk menjalin hubungan dengan orang lain.

Untuk menjaga wajah dalam berkomunikasi, penutur dan mitra tutur harus menjaga kesantunan dalam bertutur. Dalam hal ini, kesantunan berarti perilaku berbahasa dengan berdasarkan pada jarak sosial antara penutur dan mitra tutur. Apabila kesantunan tidak dijaga oleh penutur dan mitra tutur, maka jarak antara keduanya menjadi renggang dan terjadi ancaman wajah (face threatening). Pengancaman wajah terjadi ketika penutur dan mitra tutur sama-sama tidak berbahasa sesuai dengan jarak sosial (Zainurrahman, 2011). Respons at as terjadinya pengancaman wajah ini dapat dilakukan dengan kesantunan positif maupun negatif. Jika jarak sosial antara penutur dan mitra tutur dekat, maka pengancaman wajah bersifat negatif, sedangkan jika jarak antara keduanya jauh, maka pengancaman wajah bersifat positif.

\section{Strategi Kesantunan Tokoh-Tokoh Novel Kaukab Amūn}

Novel Kaukab Amūn bergenre realisme magis yang menceritakan tentang penyelamatan kaum Alkhemis Mesir di bawah Raja Amūn di Planet Amun. Strategi kesantunan berbahasa dalam novel Kaukab Amūn cukup beragam. Hal ini dikarenakan beragamnya tokoh dalam novel dari berbagai lapisan masyarakat, di antaranya Raja Amun, ratu, putri raja, pegawai kerajaan, pelayan, dan masyarakat modern. Dialog antartokoh yang memiliki strategi kesantunan paling kompleks adalah antara Syaza (Hathur) dengan Ḥūr karena status hubungan mereka dari ratu-pengawal, menjadi sepasang kekasih. Dalam melakukan komunikasi dengan raja dan keluarganya, tokohtokoh dalam novel sering menggunakan madh (pujian). Hal ini-menurut asumsi penelitidilakukan untuk menyelamatkan muka negatif mitra tutur yang memiliki kedudukan lebih tinggi daripada penutur.

Untuk menjaga berlangsungnya komunikasi yang baik antara penutur dan mitra tutur, masing-masing tokoh menggunakan strategi kesantunan, baik dengan kesantunan positif maupun kesantuan negatf. Berikut realiasasi strategi kesantunan positif dan negatif yang dilakukan oleh tokoh-tokoh novel Kaukab Amün.

\section{Strategi Kesantunan Positif}

Strategi untuk menjaga wajah positif banyak dilakukan oleh tokoh-tokoh dalam novel Kaukab Amūn, misalnya oleh tokoh Syaza, Hūr-Ān, dan direktur. Realisasi strategi kesantunan positif yang dilakukan oleh para tokoh di antaranya sebagai berikut.

a) Menghindari pertentangan/ketidakcocokan

Menghindari pertentangan merupakan salah satu strategi kesantunan untuk menjaga muka positif. Hal ini dilakukan dengan menghindari ketidakcocokan antara keduanya. Strategi kesantunan ini terwujud dalam tuturan berikut ini ketika Syaza mengusir Ḥūr dari apartemennya.

$$
\begin{aligned}
& \text { كما تأمرين يا مولاتي...أنا خادمك المطيع ولاأريد أن أسببلكي أي إزعاج لك. سأجلس على باب الغرفة في الخارج طكا كنت }
\end{aligned}
$$

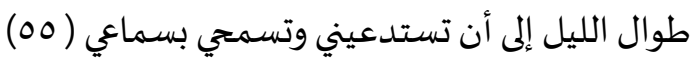


Seperti yang kau perintahkan, Ratuku. Aku adalah pelayanmu yang taat dan aku tidak ingin mengagetkanmu. Aku akan duduk di depan pintu kamarmu di luar seperti yang telah aku lakukan sepanjang malam hingga kau mengakui dan mendengarkan penjelasanku (Magdy, 2016: 55).

Pada saat pertama kali bertemu dengan Syaza, Hūr berusaha untuk menciptakan kedekatan hubungan mereka agar tujuan Ḥūr untuk membawa Syaza ke Planet Amūn tercapai. Untuk menjaga kedekatan tersebut, Ḥūr melakukan strategi kesantunan positif dengan menghindari konflik antara mereka. Syaza yang tidak mengenal Hūr sama sekali mengusir Syaza dari apartemennya. Hūr lalu menghindari konflik dengan mengucapkan kama ta'murina ya maulaty 'seperti yang kau perintahkan, Ratuku' untuk menghindari kerenggangan hubungan antara keduanya.

Strategi kesantunan positif yang sama dilakukan oleh Ḥūr ketika berusaha mendekati Syaza dan membuat komunikasi mereka berjalan lancar, seperti pada tuturan berikut.

$$
\begin{aligned}
& \text { - - مفى أرجوك..كفاك سخرية مني..ارحل } \\
& \text { ثم نهضت أمامه إلى باب الغرفة وفتحته باب الغرفة وأشارت له بالرحيل.... }
\end{aligned}
$$

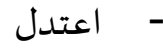

$$
\begin{aligned}
& \text { أمرك مطاع مولاتي شذى. إن أردت سماعي فأنا موجود تحت أمرك...سأجلس هنا.(OV) }
\end{aligned}
$$

"Cukup, kumohon padamu. Cukup kau memperdayaiku. Pergilah!"

Syaza lalu beranjak ke depan pintu kamar dan kemudian memberikan isyarat kepadanya untuk pergi.

"Bangunlah!"

Perintahmu ditaati, Ratuku, Syaza. Jika engkau ingin mendengarku, aku selalu bersedia mengikuti perintahmu. Aku akan duduk di sini."(Magdy, 2016: 57).

Strategi menghindari konflik dilakukan oleh Ḥūr dengan mengucapkan 'amruka muta'un maulaty Syaza 'perintahmu aku taati, Ratuku'. Strategi tersebut berhasil membuat hubungan mereka semakin dekat dan komunikasi di antara keduanya menjadi semakin lancar.

b) Melibatkan lawan tutur dalam kegiatan tertentu/aktivitas penutur

Strategi kesantunan positif dapat dilakukan dengan melibatkan mitra tutur untuk melakukan sesuatu bersama. Strategi ini dilakukan untuk menjaga wajah positif dan kedekatan penutur dan mitra tutur. Strategi mengajak mitra tutur melakukan sesuatu bersama-sama dilakukan oleh tokoh Ḥūr ketika mengajak Syaza berkeliling melihat keadaan planet Amūn berikut.

$$
\begin{aligned}
& \text { مسك يدها وحذبها فجأة وهو يضحك فصرخت بضحك وقال وهو يجري: }
\end{aligned}
$$

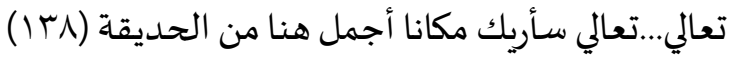

Ḥūr memegang tangannya dan kemudian tiba-tiba beteriak sambil tertawa. Lalu dia berkata, "Kemarilah, aku akan menunjukkan kepadamu tempat terindah di taman ini. (Magdy, 2016: 138).

Untuk menjaga wajah positif, Hūr melibatkan Syaza dalam aktivitasnya, yaitu berkeliling melihat-lihat keadaan planet Amun. Ajakan Ḥūr direalisasikan dalam kalimat ta'ali 'kemarilah'.

c) Menjanjikan

Strategi kesantunan positif yang berupa tindakan menjanjikan sesuatu dilakukan oleh tokoh Ḥūr kepada Syaza, seperti pada kutipan berikut.

$$
\text { فنظر لها وقال: }
$$




\section{Arabi : Journal of Arabic Studies}

'Ḥūr melayangkan pandangan kepadanya, kemudian berkata, "Aku berjanji padamu bahwa aku tidak akan menjadi orang yang kurang ajar itu, Ratuku yang cantik." (Magdy, 2016: 138).

Syaza menceritakan kehidupannya yang penuh dengan penderitaan kepada Hūr, mulai dari ditinggalkan ibunya yang menikah lagi dengan laki-laki lain dan harapan Syaza untuk mendapatkan kebahagiaan dari Hisyam juga kandas setelah dia mengkhianatinya. Huūr yang merasa sudah dekat dengan Syaza dan mulai mencintainya berjanji kepada Syaza untuk tidak menjadi seperti orang-orang yang disebutkan Syaza. Realisasi menjanjikan sesuatu diwujudkan dengan kalimat a'iduka'saya berjanji padamu'.

d) Memberi pujian kepada mitra tutur

$$
\text { أهلا بملك أمون حتب العظيم اين الإله آمون الذي يمنح النور في الظلام (مجدي، } 17 \text { ـ ب: ـ 1) }
$$

Selamat datang, Raja Amūn Hotep yang agung, putra Tuhan Amūn yang memberikan cahaya kepada seluruh kegelapan (Magdy, 2016; 102).

Pujian tersebut diucapkan oleh para pegawai kerajaan kepada Raja Amūn ketika sang raja memasuki ruang utama istana. Para pegawai kerajaan menjaga hubungan baik antara raja dan para pengikutnya. Dalam budaya Arab, rakyat banyak memberikan pujian kepada raja dengan tujuan untuk memelihara wajah positif antara raja dan para pegawai kerajaan.

Kesantunan positif yang direalisasikan dalam bentuk pujian juga dilakukan oleh Hūr kepada Syaza ketika Ḥūr melihatnya memakai pakaian kebesaran ratu sebagai berikut.

$$
\begin{aligned}
& \text { مارأيك ياحور؟ } \\
& \text { لم ينطق بحرف..وقف من مكانه وهو ينظر لها مبهورا وابتسامة تظهر على شفتيه }
\end{aligned}
$$

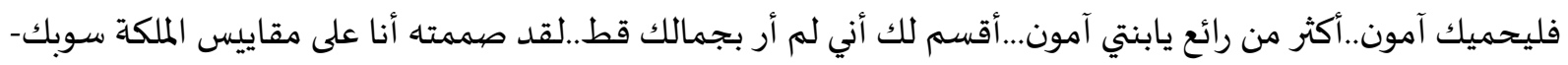

$$
\begin{aligned}
& \text { نفرو (مجدي، } 17 \text { • ץ: 109) }
\end{aligned}
$$

"Apa pendapatmu, Hūr??

(Ḥūr) tidak mengucapkan sepatah kata pun. Dia berdiri terpaku sambil melihatnya terpesona, kemudian senyuman tersungging di kedua bibirnya.

"Semoga Amūn melindungimu. Sangat indah, Wahai Putri Amun. Sungguh, aku belum pernah melihat kecantikanmu sama sekali. Aku telah mendesign (baju itu) dengan ukuran Ratu Subek-Nefru (Magdy, 2016: 109)

Tuturan tersebut menunjukkan strategi kesantunan dilakukan oleh penutur untuk menjaga kedekatannya dengan mitra tutur dengan memberikan pujian. Bentuk pujian pada tuturan tersebut adalah kecantikan Syaza yang memesona setelah dia memakai pakaian seperti ratu Subek-Nefru. Dengan pujian tersebut, mitra tutur merasa senang sehingga kedekatan jarak antara penutur dan mitra tutur terjaga dengan baik.

\section{e) Mengutarakan gurauan/melucu}

Menjaga wajah positif dapat dilakukan oleh penutur dan mitra tutur denggan mengutarakan gurauan, melucu, dan mengutarakan kalimat yang membuat mitra tutur tertawa. Hal tersebut seperti dilakukan oleh direktur kepada Syaza ketika Syaza ragu untuk menerima tawarannya menjadi pengatur pesta pernikahan putri salah satu pemimpin perusahaan tempatnya bekerja sebagai berikut.

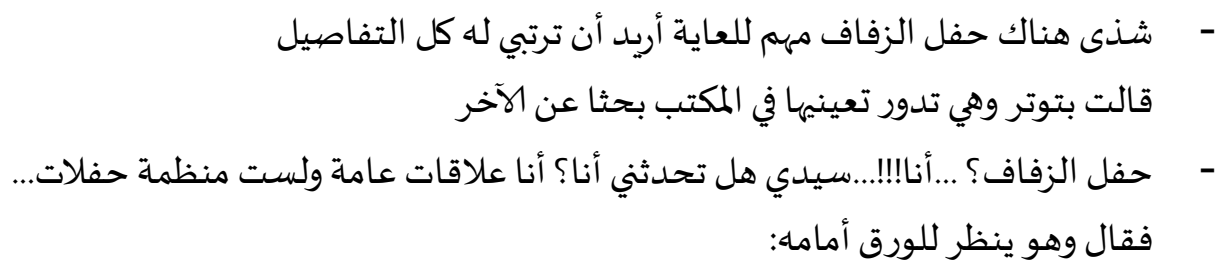




$$
\begin{aligned}
& \text { - وهل أطلب منك القيام بعملية جراحية؟.فقط سترنبين الحفل زفاف مهم لابنت لأحد أهم أعضاء النادي وطلبتك }
\end{aligned}
$$

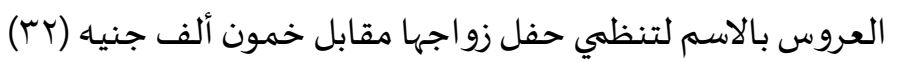

"Syaza, ada pesta pernikahan penting yang akan diadakan dan aku ingin engkau menyusun acaranya dengan detil."

Syaza menjawabnya dengan tegang sambil kedua matanya menyapu pandangan ke sekitar kantor mencari orang lain selainnya.

"Pesta pernikahan? Pak, apakah Anda berbicara kepada saya? Saya adalah pegawai humas, bukan perancang pesta."

Sang direktur berkata sambil melihat dokumen di depannya, "Apakah aku memintamu untuk melakukan oprerasi? Aku hanya ingin kamu merancang pesta pernikahan penting untuk putri salah satu orang penting di klub dan pengantin wanita memintamu secara langsung untuk merancang pesta pernikahannya dengan upah lima puluh ribu Pond.” (Magdy, 2016L 32).

Gurauan diutarakan oleh penutur dengan menggunakan kalimat 'apakah aku menyuruhmu untuk melakukan operasi'. Tentu saja, sebagai pegawai bagian humas menyusun sebuah pesta pernikahan bukanlah suatu hal yang mudah. Akan tetapi, penutur menginginkan agar mitra tutur mau memenuhi keigninan penutur. Maka, penutur mengutarakan kalimat tersebut untuk menjaga kedekatannya dengan mitra tutur sehingga dia berharap setelah terjalin kedekatan tersebut mitra tutur mau mengikuti kemauan penutur.

Strategi mengutarakan gurauan juga dilakukan oleh Syaza kepada direktur setelah dia menerima cek sebesar 50.000 Pound sebagai upahnya menyusun pesta pernikahan. Luapan kegembiraan tersebut diwujudkan dengan mengutarakan gurauan kepada mitra tutur sebagai berikut.

$$
\begin{aligned}
& \text { - - أرى أنك بعد هذا الحفل-إن أثبتني تميزك- ستتركين النادي وتتحولين للنظة أفراح... } \\
& \text { ضحكت شذى وقالت: } \\
& \text { - - إن كان الأمر هكذا يا سيدي سأقدم الاستقالةفورا و أتفرغ لتلك الأفراح ذات الخمسين الألف جنيه... } \\
& \text { رفعت الظرف أمام عينها وقالت بفرح: }
\end{aligned}
$$

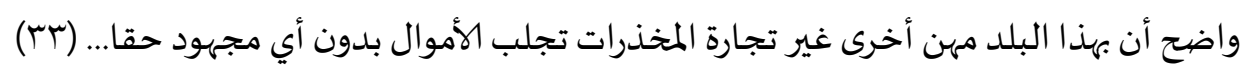

“Aku melihatmu setelah perayaan ini, jika keistimewaanmu terbukti, kau akan meninggalkan klub ini dan pindah ke perusahaan yang lebih menyenangkan...."

Syaza tertawa kemudian berkata, "Jika demikian, Pak, saya akan mengajukan pengunduran diri segera karena kebahagiaan memiliki 50.000 Pound itu."

Syaza mengangkat amplop itu ke depan matanya kemudian berkata dengan riang, "Jelaslah bahwa di negara ini ada profesi lain selain perdagangan narkoba yang bisa mendatangkan uang tanpa kerja keras." (Magdy, 2016: 33).

$$
\begin{aligned}
& \text { والتفتت إليه تغمز له بعين واحدة كمن كشفته وقالت: }
\end{aligned}
$$

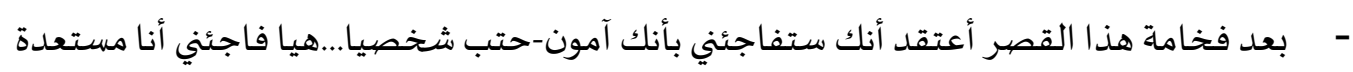

$$
\begin{aligned}
& \text { فضحك وهو يقول وقد انقطع نفسه ضحكا: } \\
& \text { بالطبع لا..صدقيني...صدقيني أنا ضابط فقط ...بيتي لايقارن بقصر الملك (9. }
\end{aligned}
$$

Syaza menoleh ke arahnya (Hur), mengerling dengan satu mata kemudian berkata, "Setelah melihat kemegahan istana ini, aku yakin kamu akan mengejutkanku bahwa engkaulah sebenarnya Amūn Hotep sendiri. Ayo kejutkan aku. Aku sudah siap."

Ḥūr tertawa, kemudian menghentikan tawanya sambil berkata, "Tentu tidak. Percayalah padaku. Percayalah, aku hanyalah seorang pengawal. Rumahku tidak bisa menyamai istana raja." (Magdy, 2016: 109). 


\section{Arabi : Journal of Arabic Studies}

f) Memberikan perhatian dan simpati

Menjaga wajah positif juga dilakukan dengan memberikan perhatian dan simpati kepada mitra tutur seperti yang dilakukan oleh ayah Hisyam ketika melihat Syaza dipermalukan di pesta pernikahan Hisyam berikut.

$$
\begin{aligned}
& \text { وانهارت إحدى أخواته وهي تترك القاعة وتصرخ بكلمة واحدة: }
\end{aligned}
$$

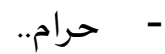

$$
\begin{aligned}
& \text { وصاح والده بصوت يكتمها البكاء: } \\
& \text { - شـذي بنيتي هيا معي...إنه ايس ابني إن أكما زبجته بتلك الخرفاء...سأرحل معك يا بنيتي (ع؟) }
\end{aligned}
$$

Salah seorang saudara perempuannya (Hisyam) meneriakkan satu kata sambil beranjak meninggalkan aula tersebut, "Haram!"

Kemudian ayahnya meneriakkan tangisan, "Syaza, Anakku, kemarilah bersamaku. Dia bukanlah anakku jika dia menyempurnakan prosesi pernikahannya dengan wanita domba itu. Aku akan pergi bersamamu, Anakku." (Magdy, 2016: 44).

Syaza dijebak oleh Zainab dengan memintanya menjadi pengatur pesta pernikahannya dengan Hisyam, kekasih Syaza. Bahkan, Zainab dan Hisyam juga mempermalukan Syaza di pesta perniakah tersebut. Keluarga Hisyam yang telah memiliki kedekatan dengan Syaza menjadi sangat marah akan perlakuan tersebut. Ayah Hisyam yang telah akrab dengan Syaza juga memahami perasaan Syaza saat itu, maka untuk menjaga kedekatan hubungan keduanya, ayah Hisyam menyatakan simpatinya kepada Syaza dan menawarinya untuk pergi bersama Syaza. Penutur menggunakan strategi tersebut untuk menjaga agar kedekatan hubungannya dengan Syaza tidak akan menjadi renggang karena peristiwa tersebut.

Strategi memberikan perhatian dan simpati juga dilakukan oleh Hūr ketika menyelamatkan Syaza dari kejadian di pesta perniakah Hisyam, seperti dalam tuturan berikut.

$$
\begin{aligned}
& \text { - يا ا أنت...ياا||...أستاذ..قف بعد إذنك. إلى أين تأخذني...قف } \\
& \text { لم يرفح عينا من على الطريق وهو يقول : } \\
& \text { - مستحيل أن أتركك بحالتك هذه...سأعود بك لمنزلك حتى لايكون هناك خطر على على حيابك يا مولاتي... }
\end{aligned}
$$

"Hai, kau, Pak...tolong berhenti. Ke mana engkau membawaku? Berhentilah!"

Lelaki itu tidak memalingkan taatapannya pada jalan, kemudian dia berkata, "Mustahil aku meninggalkanmu dalam keadaan begini. Aku akan mengantarmu ke rumahmu agar tidak ada hal yang membahayakan hidupmu, Ratu."

Penutur mengerti keadaan mitra tutur yang berada dala keadaan terguncang dan tersakiti karena telah dipermalukan di pesta pernikahan. Penutur yang sedang melakukan pendekatan kepada mitra tutur menggunakan strategi kesantunan ini untuk memperbesar keuntungan mitra tutur, yaitu dengan mengucapkan kesimpatian yang menunjukkan bahwa penutur benar-benar mengetahui keadaan mitra tutur kemudian memberikan perhatiannya kepada mitra tutur.

g) Menggunakan penanada identitas tertentu

Strategi kesantunan positif direalisasikan pula dalam bentuk menggukan sapaan tertentu. Hal ini dilakukan oleh penutur untuk menciptakan kedekatan dengan mitra tutur. Penggunaan sapaan atau identitas tertentu untuk mitra tutur seperti terdapat pada tuturan berikut.

$$
\text { صحك المدير وقال: بالتوفيق يا بنتي...ولكن الله معك (r) }
$$

Sang direktur tertawa kemudian berkata, "Selamat, Anakku. Semoga Allah selalu bersamamu." (Magdy, 2016: 33).

Penutur menggunakan sapaan binty 'anakku' untuk menunjukkan kedekatannya dengan mitra tutur. Dalam hal ini, mitra tutur merasa semakin diuntungkan karena merasa lebih dekat dengan mitra tutur yang merupakan atasannya. Strategi ini dilakukan oleh penutur agar mitra tutur merasa lebih nyaman dan dapat melakukan apa yang diinginkan penutur dengan tanpa paksaan. 
Penggunaan penanda identitas tertentu juga dilakukan oleh Ka-Him kepada Raja Amūn ketika dia menemuinya seperti pada tuturan berikut.

$$
\text { - }
$$

- Pagi yang suci berkat Amun, Tuanku.

- Ada apa, Ka-Him?

- Tuanku, perayaan penyelamatan planet akan dilaksanakan dua hari lagi dan perayaan itu tergant ung pada keberhasilan Hur-An mendatangkan Ratu Hathur." (Magdy, 2016).

Strategi yang dilakukan penutur pada tuturan di atas adalah dengan menggunakan panggilan maulaya 'rajaku' untuk mendekatkan hubungan pegawai kerajaan dengan sang raja. Dengan menggunakan sebutan tersebut, mitra tutur merasa lebih dihargai. Dengan demikian, komunikasi antara penutur dan mitra tutur menjadi semakin lancar.

h) Meminta persetujuan kepada mitra tutur

Strategi kesantunan positif dapat juga direalisasikan dalam bentuk meminta persetujuan mitra tutur, seperti pada tuturan berikut.

$$
\text { خابتيمت له وقالت: استك يا أميرتي حتحور..سأذهب لتسلم عينتك الجنية الملكية المختبر بنفسي وسأعود لك فورا.. }
$$

"Saya permisi, Ratu Hathur, saya akan pergi untuk menyerahkan sendiri sampel gen ratu ke laboratorium dan saya akan segera kembali."

Syaza tersenyum kepadanya kemudian berkata, " Gunakan waktumu, aku akan menikmati suasana di sini." (Magdy, 2016).

Para tuturan tersebut, penutur melakukan strategi kesantunan positif dengan memaksimalkan kecocokan antara keduanya dengan meminta izin kepada mitra tutur. Dengan melakukan strategi tersebut, penutur menghindari konflik dan pertentangan antara keduanya sehingga wajah keduanya tetap terjaga.

i) Menunjukkan keoptimisan

Strategi kesantunan ini dilakukan oleh tokoh Hūr kepada Syadza ketika mereka sedang berkeliling melihat-lihat planet Amun. Realisasi strategi kesantunan dengan menunjukkan keoptimisan seperti pada tuturan berikut.

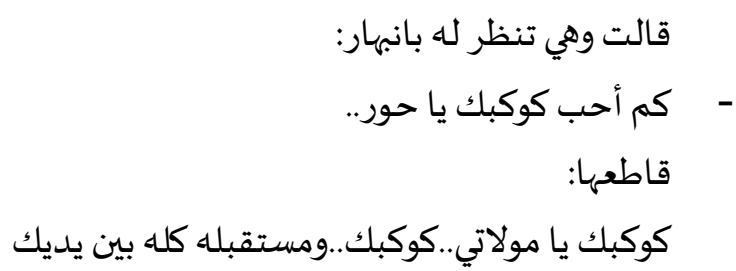
Hur."

Syaza berkata sambil melihatnya dengan merasa bangga, ”Betapa aku mencintai planetmu,

Ḥūr menyela, "Planetmu, Ratuku. Planetmu yang masa depannya semuanya ada di tanganmu." (Magdy, 2016: 126).

Pada tuturan di atas, penutur berusaha memksimalkan keuntungan mitra tutur dengan menunjukkan keoptimisan bahwa masa depan planet Amūn berada di tangan Syaza. Strategi kesantunan dengan menunjukkan keoptimisan juga dilakkan oleh tokoh Ka-Him kepada Hūr ketika Hūr akan pergi ke planet Bumi untuk mencari sang ratu penyelamat seperti tuturan berikut. 
لاتخف أعرف أنك ستتنجح وستنقذ الكوكي و سيقام الحفل بنجتح بعد ثلاثة أيام، الإنت في حضرت آمو العظيم وسوف

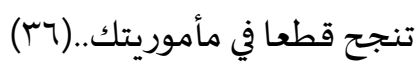

Jangan takut. Aku yakin kamu bisa selamat dan menyelamatkan planet ini dan perayaan penyelamatan planet akan dilaksanakan tiga hari lagi. Kau selalu dalam lindungan Amūn yang agung, maka engkau akan berhasil dalam misimu." (Magdy, 2016: 36).

Penut ur menyatakan keoptimisan keberhasilan misi yang dilakukan oleh mitra tutur. Dengan strategi ini, penutur memiliki maksud untuk menempatkan mitra tutur di posisi yang lebih tinggi dari penutur.

\section{Strategi Kesantunan Negatif}

Strategi kesantunan negatif dilakukan oleh tokoh-tokoh yang memiliki jarak sosial yang jauh. Tujuan dilakukannya strategi kesant unan negatif adalah agar dua orang yang memiliki jarak sosial yang jauh sama-sama merasa nyaman dan tidak berlebihan dalam berkomunikasi dengan mitra tutur. Strategi yang dilakukan untuk menjaga wajah negatif adalah sebagai berikut.

a. Menggunakan kalimat tidak langsung

$$
\text { - مولاي الملكت وقالت للمبل وصيفتي "نفرت" فور ا. أرجوك (17 ) }
$$

Syaza menoleh kemudian berkata kepada raja, "Wahai Baginda Raja, aku menginginkan pelayanku Neferti segera. Aku mohon padamu." (Magdy, 2016: 12)

Tuturan tersebut diucapkan oleh Syaza ketika dia akan berjalan menuju altar untuk melakukan prosesi penyelamatan Kaukab Amūn. Hatinya dipenuhi ketakutan karena sebentar lagi dia akan dikorbankan. Untuk menhilangkan ketakutannya itu, Syaza ingin ditemani Neferti, yang merupakan penyamaran dari Hur, kekasihnya. Maka, Syaza mengajukan permintaan kepada Amūn untuk memanggil Neferti ke altar. Amūn dan Syaza memiliki hubungan yang jauh, maka Syaza sebagai penutur menggunakan strategi wajah negatif, yaitu dengan menggunakan kalimat tidak langsung uridu wasifaty Neferti fauran 'Aku menginginkan pelayanku, Neferty segera.'

Strategi wajah negatif dengan menggunakan kalimat tidak langsung juga dilakukan oleh Hūrr pada awal pertemuannya dengan Syaza. Hūrr yang baru bertemu dengan Syaza memandang Syaza sebagai jelmaan Hathur, ratu Kaukab Amūn. Dengan demikian, kedekatan antara dia dan Syaza masih jauh, sehingga Ḥūr menggunakan strategi kalimat tidak langsung sebagai berikut.

$$
\begin{aligned}
& \text { - هكذا سهلتي على الشرح...لنجلس ونكمل حديثنا إن سمحتِ سموك وتسمعيني...فالوقوف هنا أمر مزعج حقا }
\end{aligned}
$$

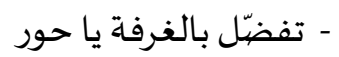

- Ini memudahkanku untuk menjelaskan, kita duduk dan menyelesaikan perbincangan kita, jika kau menghendaki, Yang Mulia, dan engkau mau mendengarkanku. Berdiri di sini benar-benar hal yang menggangguku.

- Masuklah ke kamar, Hūr Magdy, 2016).

Hūr sebenarnya meminta Syaza agar mengizikannya masuk dan menjelaskan kepadanya tentang dirinya dan misi yang dilakukannya. Syaza yang baru bertemu dengan Hūre merasa bahwa Hūr adalah orang asing yang harus dihindari. Untuk menjaga agar wajah negatif di antara keduanya tetap terjaga, Hūr sebagai penutur menggunakan kalimat berita yang memiliki maksud untuk meminta mitra tutur melakukan sesuatu, yaitu mengizinkannya masuk ke apartemen Syaza.

b. mengurangi kekuatan atau daya ancaman terhadap mitra tutur

Strategi kesantunan negatif dalam bentuk mengurangi daya ancaman terhadap mitra tutur juga dilakukan oleh Ḥūr pada awal-awal pertemuannya dengan Syaza. Hūr yang masih memiliki jarak sosial yang jauh dengan Syaza berusaha untuk menjaga agar tidak menimbulkan tekanan maupun daya ancaman, terutama ketika Syaza akan memutuskan perkara yang penting, menjadi sang ratu penyelamat Kaukab Amun. 


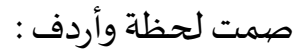

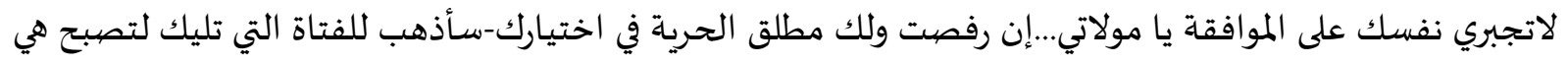

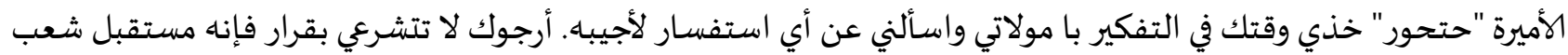

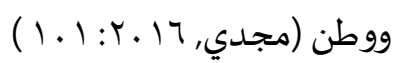

Ḥūr diam sebentar kemudian menambahkan, "Jangan memaksakan dirimu untuk menyetujuinya, Ratu. Jika engkau menolaknya, maka engkau bebas menentukan pilihanmu, dan aku akan pergi menemui gadis yang sesuai denganmu untuk menjadikannya Ratu Hatḥūr. Gunakanlah waktumu untuk berpikir, Ratu, dan bertanyalah kepadaku pertanyaan apa pun untuk kujawab. Aku mohon, jangan tergesa-gesa memutuskan karena keputusan itu adalah masa depan rakyat dan negara." (Magdy, 2016: 101).

Pada tuturan tersebut, Ḥūr menggunakan strategi wajah negatif, menempatkan dirinya sebagai kepala pengawal kerajaan. H̦ūr yang mengerti bahwa mitra tutur akan memutuskan hal yang sangat penting, menjaga jarak sosial antara keduanya menjadi lebih jauh untuk menghindari tindak ancaman dan intervensi penutur terhadap mitra tutur.

\section{c. Ungkapan permohonan maaf}

Ungkapan permohonan maaf diucapkan oleh penutur ketika melakukan tindakan yang tidak sesuai dengan keinginan mitra tutur, seperti yang dilakukan oleh Hūr ketika mereka sedang mulai berkenalan. Hūr yang mengetahui banyak tentang rusaknya kehidupan di bumi berbicara terlalu banyak tentang peristiwa-peristiwa yang terjadi di bumi. Untuk menjaga wajah negatif mitra tutur-Syaza — penutur mengungkapkan permohonan maaf sebagai berikut.

$$
\text { - أخذ نفسا عميقا اردف: }
$$

Hūr menghirup napas panjang kemudian melanjutkan, "Maafkan aku keluar dari tema pembicaraan kita, Ratu.." (Magdy, 2016: 71).

Penutur memungkapkan permintaan maafnya dengan mengucapkan i'zirini 'maafkan saya' dengan tujuan untuk meminimalkan peran penut ur yang telah terlalu banyak berbicara di luar topik utama pembicaraan mereka. Penut ur menjaga agar wajah negatif mitra tutur tetap terjaga dengan menghentikan pembicaraannya tentang kondisi planet bumi yang mulai rusak dan kurang layak dihuni.

\section{d. Memberikan penghormatan}

Strategi kesant unan negatif juga dapat dilakukan dengan memberikan penghormatan kepada mitra tutur, di antaranya dengan memberikan sapaan hormat ketika memanggil mitra tutur. Strategi kesantunan negatif dengan cara ini dilakukan oleh para pegawai kerajaan kepada Syaza yang telah berubah menjadi Hathur, sang ratu penyelamat dengan mengucapkan tuturan berikut.

$$
\text { العظمة و الاحترام يا مولاتي "حتحور" أميرنا المنقذة (مجدي، } 17 \text { ـ ؟ . . 1) ) }
$$

Keagungan dan kemuliaan, wahai Ratu Hathur, sang ratu penyelamat kami.” (Majdy, 2016: $10)$.

Penutur yang merupakan pegawai kerajaan menggunakan sapaan hormat kepada Syaza (Hathur) dengan sapaan hormat, yaitu dengan menggunakan kata 'amirati, 'ratuku', dan juga menggunakan julukan yang disematkan kepadanya, yaitu amiruna al-munqizah 'ratu penyelamat kami'. Hal tersebut dilakukan penutur untuk memaksimalkan rasa hormat penutur kepada mitra tutur yang memiliki kedudukan lebih tinggi daripada penutur, yaitu sebagai ratu mereka.

Sapaan lain yang ditujukan sebagai bentuk penghormatan diucapkan oleh Ḥūr dengan menggunakan kata sumuwun 'baginda' yang diucapkan oleh Ḥūr ketika pertama kali menerima Syaza yang telah berubah menjadi Hathur di kediamannya. 


$$
\begin{aligned}
& \text { التفت لها وقال وهو ينحني : ت ت } \\
& \text { - تشرف بيتي المتواضع بقدوم سموك يامولاتي.. } \\
& \text { ضحكت وهي تتلفت حولها وتقول : } \\
& \text { بعد هذا القصر الذي تملكه يفضل أن أقول أنا يا مولاي حور.. }
\end{aligned}
$$

Ḥūr menoleh kepadanya kemudian berkata sambil membungkuk, "Suatu kehormatan bagiku rumahkku didatangi oleh Baginda Ratu...”

Syaza tertawa sambil menoleh ke sekitarnya kemudian berkata, "Setelah istana yang kau miliki ini, akulah yang seharusnya berbicara demikian, Tuan Ḥūr..." (Majdy, 2016).

\section{Tindakan Ancaman Muka}

Tindakan ancaman muka terjadi apabila penutur maupun mitra tutur tidak berhasil melakukan strategi yang tepat dalam komunikasi. Strategi kesantunan positif berorientai pada usaha untuk menjaga muka positif mitra tutur. Menggunakan kesantunan positif dengan membayangkan bahwa pendengar memiliki dasar yang sama atau bahkan memiliki hubungan pertemanan dengan penutur dengan menggunakan yang kalimat solidaritas di antara penutur dan mitra tutur. Jika penutur dan mitra tutur memiliki jarak sosial, sedangkan mereka berkomunikasi dengan menggunakan strategi kesantunan negatif, maka terjadi tindakan ancaman muka negatif. Akibatnya, komunikasi antara penutur dan mitra tutur yang awalnya berjalan lancar, penuh solidaritas dan kedekatan menjadi renggang. Dalan keadaan tersebut, jika merasa mukanya terancam, maka penutur menggunakan strategi penyelamatan muka. Tokoh yang melakukan tindakan penyelamatan muka positif dilakukan oleh Syaza kepada Ḥūr pada tuturan berikut.

$$
\begin{aligned}
& \text { وقفت أمامه وقالت: }
\end{aligned}
$$

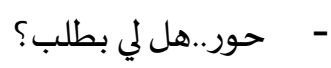

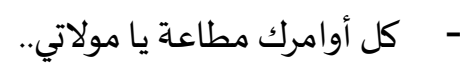

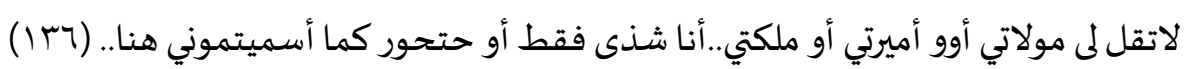

Syaza berdiri di depannya kemudian bertanya, "Hur, apakah aku boleh meminta sesuatu?"

"Segala perintahmu diikuti, Ratu."

"Jangan memanggilku dengan sebutan 'Nyonya', 'Ratuku', atau 'Baginda'. Aku adalah Syaza saja, atau Hathur, sebagaimana kalian menamaiku.” (Majdy, 2016: 132).

Syaza yang mulai akrab dengan Ḥūr merasa Ḥūr melakukan tindakan ancaman muka karena Hūr memanggilya dengan sebutan Ratu. Syaza yang merasa muka positifnya terancam melakukan tindakan penyelamatan muka dengan meminta Hūr memanggilnya dengan namanya saja, Syaza atau Hathur.

Tindakan ancaman muka negatif dilakukan oleh 'Ankh-Wa'a'Ab kepada Ḥūr ketika Ḥūr akan berangkat dari Kaukab Amūn ke Bumi untuk mencari Ratu Penyelamat.

$$
\begin{aligned}
& \text { لاتخف أعرف أنك ستتنجح وستنقذ الكوكي و سيقام الحفل بنجتح بعد ثلاثة أيام، الإنت في حضرت آمو العظيم } \\
& \text { وسوف تنجح قطعا في مأموريتك. } \\
& \text { استقام حور واقفا وقال ل" عنخ وأعب" وهو فوريك ينظر لله بعمق ويقترب منها: }
\end{aligned}
$$

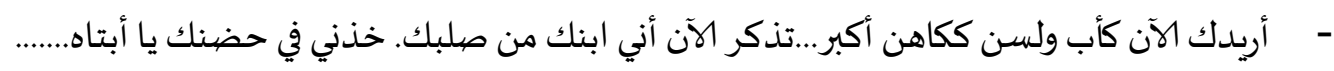

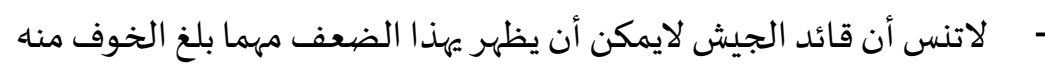

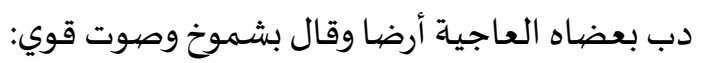

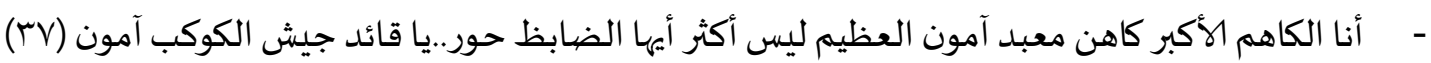


- Jangan takut, aku yakin engkau akan berhasil dan menyelamatkan planet ini dan perayaan penyelamatan planet akan dilakukan tiga hari lagi. Kau berada dalam kekuasaan Amūn yang agung, maka engkau akan sukses menjalankan misimu.

Ḥurr berdiri tegak kemudian berkata kepada 'Ankh wa A'ab sambil melihatnya dalam-dalam dan mendekat padanya,

- Aku ingin engkau bertindak menjadi ayah, bukan kepala paranormal. Katakan padaku sekarang bahwa aku adalah anakmu. Peluklah aku, Ayah."

- Jangan lupa, pemimpin pasukan tidak akan mungkin menunjukkan kelemahannya walaupun dia merasa ketakutan."

Dia menghentakkan tongkat gadingnya kemudian dia berkata dengan suara lantang,

- Aku pemimpin paranormal, paranormal tempat ibadah Amūn yang agung, tidak lebih dari itu, Prajurit Ḥūr, wahai pemimpin pasukan Kaukab Amūn.”

Sebelum berangkat menjalankan misi mencari ratu penyelamat Kaukab Amūn, Ḥūr menemui pemimpin paranormal yang juga merupakan ayahnya sendiri. Hūr yang diliputi ketakutan dan keraguan mencoba mencari dukungan dari sang ayah dengan melakukan strategi muka positif. Akan tetapi, tindakan yang dilakukan oleh Ḥūr tidak berhasil, bahkan mengancam muka negatif sang ayah, sang pemimpin paranormal. Ankh wa A'ab yang merasa mendapat ancaman muka negatif melakukan strategi penyelamatan muka negatif dengan tetap mempertahankan statusnya sebagai pemimpin paranormal dan memanggil Hūr dengan statusnya sebagai pemimpin prajurit Kaukab Amun. Strategi penyelamatan muka negatif yang dilakukan oleh Ankh wa A'ab ini diperkuat dengan tindakannya menghentakkan tongkat gadingnya dan mengatakan bahwa dia adalah pemimpin paranormal saja. Strategi yang dilakukan oleh Ankh wa A'ab tersebut berhasil mempertahankan muka negatifnya dengan Hur. Hal ini terbukti pada akhirnya Ḥūr kembali memanggil Ankh wa A'ab dengan sebutan Pemimpin Paranormal.

Ancaman muka negatif juga dialami oleh Syaza ketika dia bertemu Ḥūr untuk pertama kalinya. Syaza yang belum mengenal Ḥūr merasa terancam ketika Huūr memanggilnya dengan sebutan khusus, maulaty 'Yang Mulia' yang menunjukkan bahwa Ḥūr telah mengenal Syaza, namun Syaza menolaknya dan merasa terancam oleh tuturan Ḥūr.

$$
\begin{aligned}
& \text { - } \\
& \text { لم يرفع عينا من على الطريق وهو يقول: }
\end{aligned}
$$

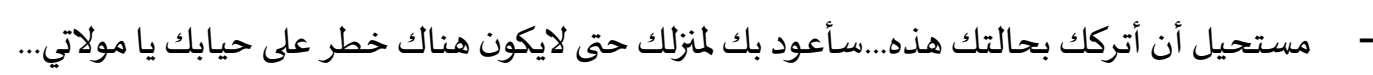

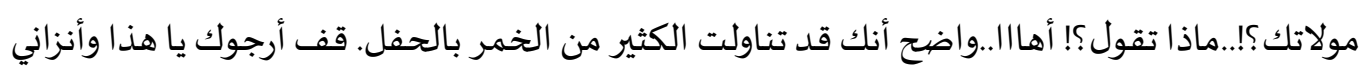

“Hai, kau! Pak...tolong berhenti. Ke mana engkau membawaku? Berhentilah!"

Lelaki itu tidak berpaling, tatapannya tetap tertuju pada jalan, kemudian dia berkata, "Tidak mungkin aku meninggalkanmu dalam keadaan begini. Aku akan mengantarmu ke rumahmu agar tidak ada hal yang membahayakan hidupmu, Ratu."

"Ratumu? Apa yang kamu katakan?! Aha, jelas bahwa kamu tadi menenggak banyak arak di dalam pesta. Berhentilah, kau, kumohon, dan turunkan aku!"

Dua orang yang belum saling mengenal tidak menggunakan sebutan khusus, seperti maulaty. Hūr merasa telah mengenal Syaza karena dia telah memiliki informasi yang lengkap tentang Syaza dan kehidupannya, Amūn tidak menyadari bahwa Syaza belum mengenalnya. Oleh sebab itu, Ḥūr melakukan tindakan ancaman muka negatif terhadap Syaza. Untuk mengatasi ancaman muka tersebut, Syaza melemparkan tuturan yang memaksimalkan keuntungan dirinya, yaitu dengan mengatakan bahwa Hūr terlalu banyak minum di pesta pernikahan.

Raja Amūn melakukan tindakan penyelamatan muka negatif ketika Subek Nefru berusaha melanggar perintahnya untuk tetap tinggal di Bumi, memerintah kerajaan Amūn di Bumi.

$$
\text { - اتتركني هطذا يا أبتاه...لاتفعل بي هذا..أنا سوبك-نفرو ابنتك الحبيبة..لاتتركني أرجوك..خذني معك وابق معي }
$$




$$
\begin{aligned}
& \text { وقف والدها ونزل عن العرش خطوات وقال وهو يرحل وظهره لها: } \\
& \text { - استعدي للحكم وحدك وزفافك على آمون محات الرابع..إن هذا أمر ملكي }
\end{aligned}
$$

'Subek Nefru berkata sambil menangis, "Jangan tinggalkan aku, Ayah. Jangan lakukan ini padaku. Aku Subek Nefru anak perempuan kesayanganmu. Jangan tinggalkan aku, kumohon. Bawalah aku bersamamu dan tinggallah bersamaku.

Sang ayah berdiri, lalu turun beberapa langkah dari tahtanya, kemudian pergi meninggalkannya sambil berkata, "Bersiaplah untuk naik tahta dan pernikahanmu denga Amūn Mahat IV. Ini adalah perintah raja."

Sebagai raja yang perintahnya selalu diikuti, Raja Amūn merasa terancam karena mitra tutur mengurangi keuntungan dan menurunkan rasa hormatnya kepadanya. Subek Nefru yang mengingkari perintah Amūn mencoba melakukan strategi kesantunan positif dengan menempatkan dirinya sebagai putri Amun. Akan tetapi, strategi yang dilakukan oleh Subek Nefru berakibat pada pengancaman muka negatif Raja Amūn. Maka, untuk melakukan penyelamatan wajah negatif, Amūn kembali membuat jarak antara dirinya dan Subek Nefru yang menyatakan bahwa dirinya adalah raja dan perintahnya harus diikuti.

\section{Simpulan}

Untuk menjalin komunikasi yang lancar dan harmonis, penutur dan mitra tutur dalam novel Kaukab Amūn menggunakan strategi kesantunan positif dan negatif. Strategi kesantunan positif dilakukan dengan tujuan untuk menjaga kedekatan antara penutur dan mitra tutur. Strategi kesantunan positif direalisasikan dengan bentuk menghindari pertentangan, melibatkan lawan tutur dalam kegiatan tertentu/aktivitas penutur, menjanjikan sesuatu kepad mitra tutur, memberi pujian kepada mitra tutur, mengutarakan gurauan/melucu, memberikan perhatian dan simpati, menggunakan penanada identitas tertentu, meminta persetujuan kepada mitra tutur, dan menunjukkan keoptimisan. Adapun strategi kesantunan negatif dilakukan dengan menggunakan kalimat tidak langsung, mengurangi kekuatan atau daya ancaman terhadap mitra tutur, menggunakan ungkapan permohonan maaf, dan memberikan penghormatan kepada mitra tutur. Dalam dialog antartokoh dalam novel Kaukab Amūn terjadi tindakan ancaman muka, baik muka positif maupun muka negatif. Tindakan ancaman muka positif dilakukan oleh tokoh Hūr kepada Syaza. Adapun tindakan ancaman muka negatif ditemukan lebih banyak, yaitu dilakukan oleh Ankh wa A’ab kepada Hur, Ḥūr kepada Syaza, serta Subek Nefru kepada Raja Amun.[]

\section{Daftar Rujukan}

Aziz, E. A. (2000). Refusing in Indonesian: Strategies and Politeness Implications. Disertasi, Australia: Monash University.

Aziz, E. A. (2008). Horison Baru Teori Kesantunan Berbahasa: Membingkai yang Terserak, Menggugat yang Semu, Menuju Universalisme yang Hakiki. Pidato Pengukuhan Guru Besar, Indonesia: Universitas Pendidikan Indonesia.

Brown, P \& S.C. Levinson. (1987). Universals in Language Usage: Politeness Phenomena. In E.N. Goody (ed). Questions and Politeness: Strategies in social interaction, 56-289. Cambridge: Cambridge University Press.

Farenkia, Bernard Mulo. 2014. Face-Enhancing Strategies in Compliment Responses. Department of Languages and Letters, Cape Breton University

Feghali, Ellen. 1997. Arab Cultural Communication Patterns. Inr. J. Ink-rculfural Rel. Vol 21, No. 3, pp. 345-378, 1997

Gunawan. The Pragmatic Force of Political Campaign. Proceeding of Annual Conference on Islamic Studies. 
Arabi : Journal of Arabic Studies

Hamed, Ayman Mohamed Elsoufi. 2014. A Contrastive Study of Politeness and Impoliteness Strategies in British and Arab Sports Media Discourse. Faculty of Arts Fayoum University

Leech, Geoffrey. 1993. Prinsip-prinsip Pragmatik (Diterjemahkan oleh M.D.D. Oka dan Setyadi Setyapranata). Jakarta: Penerbit Universitas Indonesia.

Maan Muhammed Aubed. 2012. Polite Requests in English and Arabic: A Comparative Study. Iraq: College of Arts, University of Tikrit, Tikrit, Iraq

al-Qahtani, Hanaa Ali. 2005. Female Use of Politeness Strategies in the Speech Act of Offering:A Contrastive Study between Spoken Saudi Arabic and Spoken British. Damascus University Journal, Vol.21, No. (3+4), 2005 Nafez A. Shammas

Rahardi, R. Kunjana. 2000. Imperatif Dalam Bahasa Indonesia. Yogyakarta: Duta Wacana University Press.

Sudaryanto, 1993. Aneka Metode dan Teknik Penelitian Bahasa. Yogyakarta: Pustaka Pelajar

Wijana, I Dewa Putu. 2006. Dasar-Dasar Pragmatik. Yogyakarta. Andi Offset.

Wijayanto, Agus, dkk. 2013. Politeness in Interlanguage Pragmatics of Complaints by Indonesian Learners of English. FKIP Universitas Muhammadiyah Surakarta.

Yule, George. 1996. Pragmatics. Oxford: Oxford University Press.

Zainurrahman, "Telaah Pragmatik atas Konsep Wajah dalam Kesantunan Berbahasa" dalam https://zainurrahmans.wordpress.com diunggah pada tahun 2011 diunduh pada 23 Februari 2017. 